\title{
Apical conicity ratio: A new index on left ventricular apical geometry after myocardial infarction
}

\author{
Hongguang Fan, MD, ${ }^{\mathrm{a}}$ Zhe Zheng, MD, ${ }^{\mathrm{a}}$ Wei Feng, MD, ${ }^{\mathrm{a}}$ Yan Zhang, MD, ${ }^{\mathrm{b}}$ Lixin Jin, MD, PhD, ${ }^{\mathrm{c}}$ \\ Peng Li, MD, ${ }^{\mathrm{b}}$ and Shengshou Hu, MD, FACC ${ }^{\mathrm{a}}$
}

Objective: Our objective was to introduce a new index to evaluate left ventricular aneurysm by quantitative analysis of left ventricular apical geometry.

\begin{abstract}
Methods: A total of 116 selected subjects underwent magnetic resonance imaging, 28 healthy volunteers, 29 patients with dilated cardiomyopathy, and 59 patients with ischemic heart disease ( 26 with left ventricular aneurysm; 33 with no aneurysm). The apical conicity ratio was calculated as the ratio of left ventricular apical area over apical triangle.
\end{abstract}

\begin{abstract}
Results: Diastolic apical conicity ratio of patients with left ventricular aneurysm was $1.62 \pm 0.20$ and systolic apical conicity ratio was $1.78 \pm 0.43$. After left ventricular reconstruction, the diastolic apical conicity ratio decreased to $1.47 \pm 0.23$ and the systolic ratio to $1.51 \pm 0.21$, which came close to the normal level, whereas other global indices remained. In patients with dilated cardiomyopathy, sphericity index and eccentricity index increased significantly without changes in the apical conicity ratio. Among patients with ischemic heart disease, the apical conicity ratio of the group with left ventricular aneurysm was significantly higher than that of the group without an aneurysm when the other indices between the 2 groups showed no statistically difference. Receiver operating characteristic curves showed only apical conicity ratio had high power of discriminating left ventricular aneurysm from no aneurysm.
\end{abstract}

Conclusions: The new index, apical conicity ratio, can be used to quantify the regional left ventricular deformation, especially in patients with left ventricular aneurysm resulting from myocardial infarction. (J Thorac Cardiovasc Surg 2010;140:1402-7)

Supplemental material is available online.

Ventricular remodeling is an inevitable pathophysiologic process in the heart after acute myocardial infarction and may contribute to heart failure, left ventricular aneurysm (LVA), and poor prognosis. Recently, the significance of apical conical configuration in maintaining left ventricular contractile efficiency has been recognized. ${ }^{1-4}$ Surgical treatment

From the Department of Cardiovascular Surgery and Research Center for Cardiovascular Regenerative Medicine ${ }^{\mathrm{a}}$ and the Department of Imaging, ${ }^{\mathrm{b}}$ Cardiovascular Institute and Fu Wai Hospital, Peking Union Medical College \& Chinese Academy of Medical Sciences, Beijing, China; and Collaboration Team, ${ }^{\mathrm{c}}$ Siemens Ltd, China (Shanghai), SIMZ, Siemens S\&T Park, Shanghai, China.

This work was supported by the National Science \& Technology Pillar Program (grant No. 2006BAI01A09), Beijing Municipal Science \& Technology Commission (grant No. D0906004040391), and Program for Changjiang Scholars and Innovative Research Team in University.

Disclosures: None.

Received for publication Oct 22, 2009; revisions received Jan 10, 2010; accepted for publication Feb 8, 2010; available ahead of print April 12, 2010.

Address for reprints: Shengshou Hu, MD, FACC,${ }^{1}$ Cardiovascular Institute and Fuwai Hospital, Chinese Academy of Medical Science, Department of Cardiac Surgery, Beilishi Rd 167, Beijing, Beijing 100037, China (E-mail: shengshouhu@yahoo. com).

$0022-5223 / \$ 36.00$

Copyright (C) 2010 by The American Association for Thoracic Surgery doi:10.1016/j.jtcvs.2010.02.017 for LVA involved not only reduction of ventricular volume, but also left ventricular reshaping. How to assess the left ventricular geometry, especially for apical morphology, becomes an issue of concern to the cardiac surgeon. Several indices, such as sphericity index (SI), volumetric sphericity index (vSI), and eccentricity index (EI), are often used to evaluate global left ventricular morphology ${ }^{5-7}$ but cannot be used for assessing regional left ventricular deformation. It has been demonstrated in previous studies that Fourier shape analysis ${ }^{7-10}$ precisely quantifies left ventricular geometry; nevertheless, it is rarely applied clinically owing to its complex and time-consuming procedure. To date, there is not a clinically useful index of regional left ventricular deformation. In this study, we introduce a new index, apical conicity ratio (ACR), representing the ratio of the area of left ventricular apex over the apical triangle on a 2-chamber view image, which accurately evaluates the extent of apical geometric deviations from normal shape.

\section{METHODS \\ Patient Selection}

Twenty-six patients with LVA underwent left ventricular reconstruction and surgical revascularization concomitantly. Magnetic resonance imaging (MRI) before and after surgical ventricular restoration was evaluated. The operation was performed with cardiopulmonary bypass and aortic clamping. Moderate systemic hypothermia $\left(28^{\circ} \mathrm{C}-30^{\circ} \mathrm{C}\right)$ and antegrade cold blood cardioplegia were used. An incision parallel to the left anterior descending artery 


$$
\begin{aligned}
& \text { Abbreviations and Acronyms } \\
& \begin{array}{ll}
\text { ACR } & =\text { apical conicity ratio } \\
\text { DCM } & =\text { dilated cardiomyopathy } \\
\text { EDV }(\mathrm{I}) & =\text { end-diastolic volume (index) } \\
\text { EI } & =\text { eccentricity index } \\
\text { ESV }(\mathrm{I}) & =\text { end-systoc volume (index) } \\
\text { IHD } & =\text { ischemic heart disease } \\
\text { LVA } & =\text { left ventricular aneurysm } \\
\text { MRI } & =\text { magnetic resonance imaging } \\
\text { ROC } & =\text { receiver operating characteristic } \\
\text { SI } & =\text { sphericity index } \\
\text { SV(I) } & =\text { stroke volume (index) } \\
\text { VSI } & =\text { volumetric sphericity index }
\end{array}
\end{aligned}
$$

was made within the infarcted anterior wall segment and any thrombus carefully removed. The junctional borders were visible in most cases; palpation was helpful in the presence of an unclear border. An endoventricular pursestring suture was placed with a 1-0 Prolene polypropylene line (Ethicon, Inc, Somerville, NJ). The suture was placed in the scarred tissue above the junctional zone, and deep bites were made into the half thickness of this tissue to apply sufficient and lasting tension. The suture was then tied to rebuild the ventricular shape and created an opening about $2 \mathrm{~cm}$ in diameter. The ventricular chamber was reduced and kept in satisfactory geometry. The ventriculotomy was closed with 1-0 Prolene polypropylene line as heavy horizontal mattress sutures buttressed in polytetrafluoroethylene and reinforced by continuous sutures. In this process, the stitch sites were adjusted occasionally to avoid deforming the ventricular shape. ${ }^{11,12}$ If concomitant coronary artery bypass grafting was to be performed, all distal anastomoses were performed during the same aortic crossclamp period, and proximal anastomoses were performed during the rewarming period. The operations were performed by 5 surgeons who were not aware of ACR and the study design. The criterion for patient selection was that the patient undergo coronary artery bypass grafting with a dyskinetic segment exceeding $30 \%$ of the left ventricular perimeter on right anterior oblique ventriculography.

Thirty-three patients with ischemic heart disease without LVA (nonLVA), 29 patients with dilated cardiomyopathy (DCM), and 28 healthy volunteers were selected as control. The non-LVA group had 33 patients ( 23 men and 10 women; mean age $56.0 \pm 9.2$ years) with previous myocardial infarction, and all of the patients underwent surgical revascularization. The DCM group comprised 29 patients ( 21 men and 8 women; mean age $44.9 \pm 14.8$ years) in whom angiography had proved the absence of coronary artery disease. The healthy group included 28 healthy volunteers (26 men and 2 women; mean age $30.6 \pm 3.9$ years) with no history or physical finding of cardiac or pulmonary disease. All patients with ischemic heart disease (IHD) received preoperative echocardiography and left ventricular angiographic examinations to determine dyskinetic LVA. This study was approved by the Institutional Review Board at Fu Wai Hospital. All patients gave written informed consents.

\section{MRI Technique}

A 1.5-T whole-body scanner (Avanto, Siemens Healthcare, Erlangen, Germany) was used for MRI scanning with the subjects in the supine position. The system was capable of operating at a maximum slew rate of $200 \mathrm{mT} / \mathrm{m}$ and a maximum gradient strength of $40 \mathrm{mT} / \mathrm{m}$. Twelve-element matrix coils ( 6 anterior and 6 posterior) equipped with the scanner and wireless physiologic measurement unit were activated for data acquisition wireless vector cardiographic gating triggering.

All imaging acquisitions were captured under breath control. Scout transversal and sagittal images were acquired followed by a half-Fourier acquisition single shot turbo spin echo sequence (HASTE: repetition time/ echo time $=700 / 42 \mathrm{~ms}$, voxel size $=2.5 \times 1.5 \times 6.0 \mathrm{~mm}$, flip angle $=160^{\circ}$ ) for the exact determination of long-axis (left ventricle, 2-chamber view: along the line through the base of the heart and the middle of the mitral valve on axial images), 4-chamber (along the line through the base of the heart and the middle of the mitral valve on 2-chamber images), and short-axis (2-chamber view: perpendicular to the line through the base of the heart and the middle of the mitral valve on 4-chamber view) plane position. True imaging with steady-stage precession sequence (TrueFisp) was chosen for cine scan in the long- and short-axis views with the following parameters: repetition time $/$ echo time $=4.0 / 1.1 \mathrm{~ms}$, voxel size $=2.0 \times 2.0 \times 6.0 \mathrm{~mm}$, flip angle $=62^{\circ}$; each section was then acquired in a single breath hold in 8 to 14 seconds with 15 to 25 temporal phases per heartbeat.

Contrast-enhanced images were acquired approximately 15 minutes after bolus injection of gadolinium diethylenetriamine pentaacetic acid (Magnevist, Schering, Berlin, Germany; $0.15 \mathrm{mmol} / \mathrm{kg}$ or $0.20 \mathrm{mmol} / \mathrm{kg}$ ) with an inversion-recovery 3-dimensional spoiled gradient echo sequence; inversion time was determined with real-time plan scan. Typical parameters were a field of view of $400-400 \mathrm{~mm}^{2}$, matrix of 256-256 pixels, slice thickness of $5.00 \mathrm{~mm}$, overlapping slices (50\%), flip angle of $15^{\circ}$, time to echo of $1.36 \mathrm{~ms}$, and time to repeat of $4.53 \mathrm{~ms}$.

\section{Imaging Analysis}

For analysis, the MRIs were transferred to a multimodality station with a Windows platform system. Endocardial and epicardial borders of the left ventricle were traced with an automatic segmentation method, from which the basic heart shape and functional parameters, such as end-systolic volume (ESV), end-diastolic volume (EDV), stroke volume (SV), left ventricular ejection fraction, and cardiac output, were calculated automatically. ESV, EDV, $\mathrm{SV}$, and cardiac output were standardized as end-systolic volume index (ESVI), end-diastolic volume index (EDVI), stroke volume index (SVI), and cardiac index by body surface area. Long-axis length was measured in 2-chamber view from the apex to the midpoint of the mitral valve and shortaxis length was measured on the line that was perpendicular to the long-axis line at the level of the midpoint of the long axis. From the same view, the apical area was measured as the area of blood pool from the short-axis level to apex. The value was calculated automatically by manually tracing endocardial contour through an interactive interface. The apical triangle area was calculated by the length of the long axis and short axis (Figure 1, Figure E1).

Contrast-enhanced images were scored visually using the 17-segment model as recently proposed. ${ }^{13}$ Each segment was graded on a 5-point scale (segmental scar score): 0 , absence of hyperenhancement; 1 , hyperenhancement of $1 \%$ to $25 \%$ of left ventricular wall thickness; 2 , hyperenhancement extending to $26 \%$ to $50 \%$; 3 , hyperenhancement extending to $51 \%$ to $75 \%$; and 4 , hyperenhancement extending to $76 \%$ to $100 \% .{ }^{14}$ All imaging parameters were obtained and analyzed blindedly by 2 trained clinical observers separately.

\section{Parameters Calculation}

SI, vSI, EI, and ACR were calculated according to formulas 1 through 4 , respectively. SI and vSI were unitless indices ranging from 0 for a line, in which short axis $=0$, to 1 for a circle, short axis $=$ long axis. On the contrary, EI ranged from 0 for a circle, in which short axis = long axis, to 1 for a line, in which long axis $=0$. ACR is an index theoretically always larger than 1 . The larger the value, the more deformation of the left ventricular apex.

$$
\begin{aligned}
& S I=\frac{S A}{L A} \quad(\text { Formula } 1)^{15} \\
& v S I=\frac{6 L V V}{\pi L^{3}} \quad(\text { Formula 2) })^{16}
\end{aligned}
$$



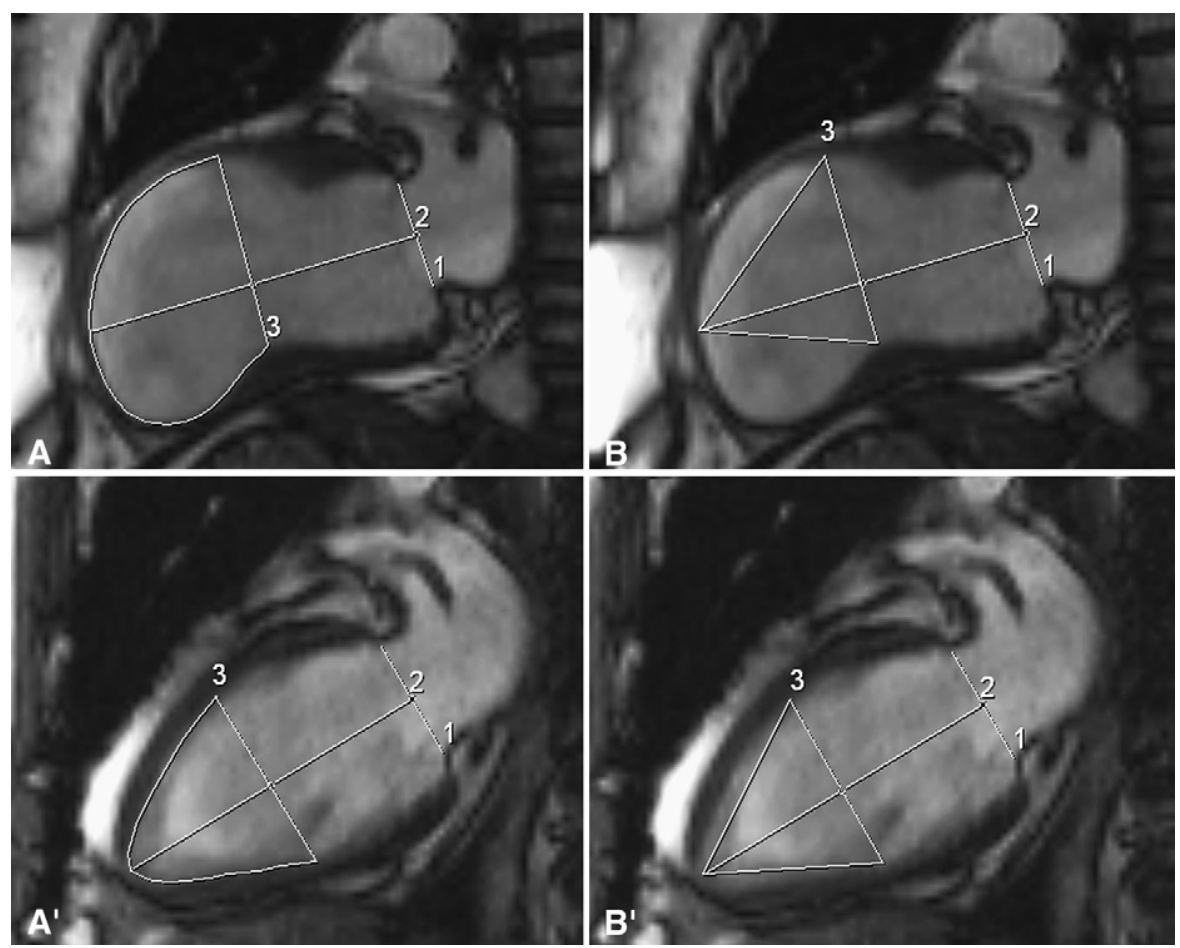

FIGURE 1. The magnetic resonance images and schematic diagrams depicted the 2-chamber view used to measure the areas of apical area and apical triangle in a patient (image $\mathrm{A}$ and $\mathrm{B}, \mathrm{ACR}=2.05$ ) and a healthy (image $\mathrm{A}^{\prime}$ and $\mathrm{B}^{\prime}, \mathrm{ACR}=1.24$ ). Long-axis length was measured in 2-chamber view from the apex to the midpoint of the mitral valve and short-axis length was measured as the axis that perpendicularly intersects the midpoint of the long axis. The apical area was defined as the area of blood pool from the short axis to apex and its value was measured automatically by tracing of endocardial contour through an interactive interface $\left(\mathrm{A}, \mathrm{A}^{\prime}\right)$. The apical triangle area was calculated by the length of long axis and short axis $\left(\mathrm{B}, \mathrm{B}^{\prime}\right)$. ACR was the ratio of the area of apex over the area of apical triangle.

$$
\begin{gathered}
E I=\frac{\sqrt{L A^{2}-S A^{2}}}{L A} \quad(\text { Formula } 3)^{6,7} \\
A C R=\frac{S_{a p}}{S_{a t}}=\frac{4 S_{a p}}{S A \cdot L A} \quad(\text { Formula } 4)
\end{gathered}
$$

where SA is short axis, LA is long axis, LVV is left ventricular volume, and $\pi \cdot$ LA.

\section{Statistical Analysis}

Data were presented as mean \pm standard deviation (SD). The normal distribution variables were tested by the Kolmogorov-Smirnov test. Distribution differences of variables between patients and healthy controls were tested by the $t$ test in case of normally distributed variables and by the Mann-Whitney $U$ test if variables were not normally distributed. Pearson's test was used to determine the correlationship between ACR and scar score.

To determine the power of the different indices to discriminate between LVA patients from IHD, we calculated a receiver operating characteristic (ROC) curve for each parameter of the dataset. Two different a priori hypotheses were specified, that is, that smaller or larger parameter values showed stronger evidence of positivity (LVA). The area under the ROC curve is calculated, whereby an area index of 0.5 indicates a poor diagnostic test, while a value of 1.0 indicates an ideal test. An area index less than 0.5 shows that the a priori hypothesis should be changed.

For diastolic and ACR, sensitivity and specificity were calculated at different cutoff points. The respective highest sensitivity and specificity were obtained at the optimal cutoff value, which is estimated by the Youden index. ${ }^{17}$
Statistical analysis was carried out using SPSS for Windows (SPSS version 15.0, SPSS Inc, Chicago, Ill).

\section{RESULTS \\ ACR and Ventricular Shape}

The differences of general shape and function between healthy controls and patients are shown in Table 1 . The general parameters of each group of patients, including the length of diastolic long axis, length of systolic long axis, length of diastolic short axis, length of systolic short axis, ESVI, SVI, left ventricular ejection fraction, and cardiac index, were significantly different from the healthy controls. Among the patient groups, most of these parameters on primary left ventricular shape and function of the DCM group were statistically different from the LVA groups. The shape indices of different groups, including diastolic SI, systolic SI, diastolic vSI, systolic vSI, diastolic EI, systolic EI, diastolic ACR, and systolic ACR, are shown in Figure 2. The SI, vSI and EI of the DCM group were distinguished from those of healthy and LVA groups, but those in healthy and LVA groups they were similar. However, the ACR of the LVA group was higher than that of any other groups.

In patients with LVA, the general parameters, including diastolic and systolic long axis, diastolic and systolic short 
TABLE 1. General left ventricular geometry and heart function in healthy controls and patients

\begin{tabular}{|c|c|c|c|}
\hline & $\begin{array}{l}\text { Healthy } \\
(\mathbf{n}=\mathbf{2 8})\end{array}$ & $\begin{array}{c}\text { DCM } \\
(\mathbf{n}=\mathbf{2 9})\end{array}$ & $\begin{array}{c}\text { LVA } \\
(\mathrm{n}=\mathbf{2 6})\end{array}$ \\
\hline $\mathrm{LA}_{\mathrm{d}}(\mathrm{cm})$ & $9.32 \pm 0.75$ & $10.53 \pm 0.84^{*}$ & $10.16 \pm 0.91^{*} \ddagger$ \\
\hline $\mathrm{LA}_{\mathrm{s}}(\mathrm{cm})$ & $7.00 \pm 0.94$ & $9.99 \pm 1.05^{*}$ & $9.72 \pm 0.99 *$ \\
\hline $\mathrm{SA}_{\mathrm{d}}(\mathrm{cm})$ & $5.68 \pm 0.55$ & $7.75 \pm 1.30^{*}$ & $6.01 \pm 0.52 \S$ \\
\hline $\mathrm{SA}_{\mathrm{s}}(\mathrm{cm})$ & $3.57 \pm 0.57$ & $7.42 \pm 1.41 *$ & $5.13 \pm 0.70^{*} \S \S$ \\
\hline $\operatorname{EDVI}\left(\mathrm{mL} / \mathrm{m}^{2}\right)$ & $79.10 \pm 11.14$ & $172.97 \pm 78.05^{*}$ & $93.75 \pm 25.25^{*}, \S$ \\
\hline $\operatorname{ESVI}\left(\mathrm{mL} / \mathrm{m}^{2}\right)$ & $28.05 \pm 7.36$ & $147.36 \pm 75.09^{*}$ & $69.11 \pm 26.17 \dagger^{\prime}$ \\
\hline $\operatorname{SVI}\left(\mathrm{mL} / \mathrm{m}^{2}\right)$ & $44.79 \pm 8.69$ & $25.98 \pm 10.90^{*}$ & $24.27 \pm 6.44 \ddagger$ \\
\hline $\operatorname{LVEF}(\%)$ & $67.45 \pm 12.76$ & $16.53 \pm 7.41^{*}$ & $27.79 \pm 8.76 \dagger ' \S$ \\
\hline $\mathrm{CI}\left(\mathrm{L} \cdot \min ^{-1} \cdot \mathrm{m}^{-2}\right)$ & $2.87 \pm 0.58$ & $2.54 \pm 2.84^{*}$ & $1.75 \pm 0.40 \dagger{ }^{\prime} \S$ \\
\hline
\end{tabular}

$D C M$, Dilated cardiomyopathy; $L V A$, left ventricular aneurysm; $L A_{d}$, length of diastolic long axis; $L A_{s}$, length of systolic long axis; $S A_{d}$, length of diastolic short axis; $S A_{s}$, length of systolic short axis; $E D V I$, end-diastolic volume index; $E S V I$, endsystolic volume index; $S V I$, stroke volume index; $L V E F$, left ventricular ejection fraction; $C I$, cardiac index. DCM, LVA versus healthy. $* P<.05 . \dagger P<.01$. DCM

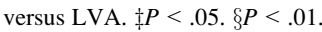

axis, EDVI, ESVI, and left ventricular ejection fraction, were significantly different preoperatively from postoperatively. The diastolic ACR of patients with LVA was $1.62 \pm 0.20$ and the systolic ACR was $1.78 \pm 0.43$. After left ventricular aneurysmectomy, diastolic ACR decreased
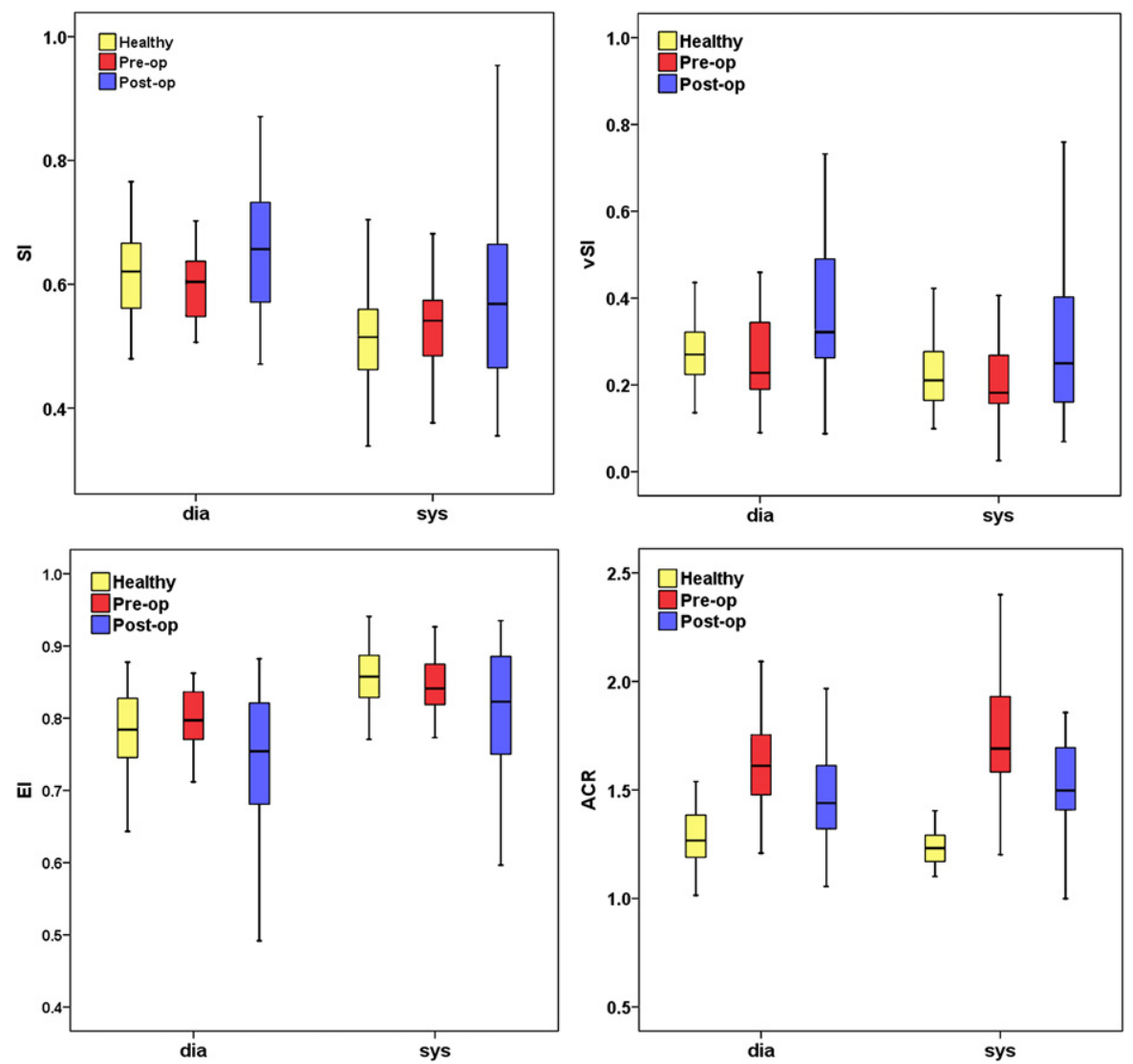

FIGURE 3. Comparison of indices in health control and patients with left ventricular aneurysm preoperatively and postoperatively (n $=24)$. SI, Sphericity index; $v S I$, systolic volumetric sphericity index; $E I$, eccentricity index; $A C R$, apical conicity ratio. 


\section{ACR and IHD}

In the population of patients with IHD, both diastolic and systolic ACR demonstrated significant correlation with scar score (diastolic ACR: $r=0.638, P<.01$; systolic ACRs: $r=0.773, P<.01$ ) (Figure E2).

There was no difference between the LVA and non-LVA groups on the general left ventricular geometry and function. However, the ACRs of LVA groups were significantly higher than those of non-LVA group, whereas the other indices between the 2 groups showed no statistically significant difference (Table 2).

ROC curves and the area under curves were calculated as SI, vSI, EI, and ACR. The optimal cutoff values were set for shape indices with an area index greater than 0.7. The best discriminators between LVA and non-LVA are presented as ROC curves in Figure E3. Table E2 shows the area under curves for these variables for the assumptions that large values provide stronger evidence for LVA. Only diastolic ACR (area under curve: 0.969; cutoff value: 1.43; sensitivity: $92.3 \%$; specificity: $87.9 \%$ ) and systolic ACR (area under curve: 0.929 ; cutoff value: 1.49 ; sensitivity: $92.3 \%$; specificity: $93.9 \%$ ) showed high discriminating power.

\section{DISCUSSION}

Since Hutchins, Brawley, and their associates ${ }^{18,19}$ first emphasized the importance of left ventricular geometry in the repair of LVA, many experimental and clinical studies have explored the significance of the normal ventricular shape. The conical pattern of normal ventricular size and shape was widely recognized and further studies discovered the dominant role of the left ventricular geometry on the transmural and longitudinal left ventricular twist patterns. ${ }^{20} \mathrm{Af}-$ ter myocardial infarction, the helical apex is lost and becomes replaced by a sphere. The structural consequence is that the oblique apical loop fibers become more transverse, so that the fiber orientation of the apical loop begins to resemble the basal loop. The bioengineering infrastructure for this mechanical change in size and shape reduces left ventricular ejection fraction. ${ }^{1,4}$ In addition to this, recent studies showed that left ventricular geometry is not only related to systolic function, ${ }^{21}$ but also related to circulating biomarker and a sensitive predictor of cardiovascular events. ${ }^{22}$ There is evidence that left ventricular geometry is an important intermediate phenotype to study of cardiovascular diseases. Precise and intensive evaluations of left ventricular geometry are fundamental. ${ }^{23-25}$

There are many conventional measurements of left ventricular geometry including SI, vSI, and EI, which can be used to evaluate the global left ventricular shape and have been applied clinically. ${ }^{5-7}$ LVA, mostly located at the apex either anterolaterally or posteriorly after transmural infarctions, is often evaluated by left ventriculography and echocardiography. ${ }^{26,27}$ Owing to irregularity of aneurysm boundary, it is difficult to precisely assess aneurysm size, but
TABLE 2. General left ventricular geometry, heart function, and indices in IHD patients $(n=59)$

\begin{tabular}{|c|c|c|c|}
\hline & $\begin{array}{l}\text { Healthy } \\
(n=28)\end{array}$ & $\begin{array}{c}\text { Non-LVA } \\
(n=33)\end{array}$ & $\begin{array}{c}\text { LVA } \\
(n=26)\end{array}$ \\
\hline $\mathrm{LA}_{\mathrm{d}}(\mathrm{cm})$ & $9.32 \pm 0.75$ & $9.96 \pm 0.68$ & $10.07 \pm 0.10$ \\
\hline $\mathrm{LA}_{\mathrm{s}}(\mathrm{cm})$ & $7.00 \pm 0.94$ & $9.27 \pm 0.81$ & $9.79 \pm 1.13$ \\
\hline $\mathrm{SA}_{\mathrm{d}}(\mathrm{cm})$ & $5.68 \pm 0.55$ & $6.07 \pm 0.83$ & $6.06 \pm 0.79$ \\
\hline $\mathrm{SA}_{\mathrm{s}}(\mathrm{cm})$ & $3.57 \pm 0.57$ & $5.46 \pm 1.01$ & $5.30 \pm 0.87$ \\
\hline $\operatorname{EDVI}\left(\mathrm{mL} / \mathrm{m}^{2}\right)$ & $79.10 \pm 11.14$ & $105.13 \pm 45.90$ & $115.84 \pm 40.46$ \\
\hline $\operatorname{ESVI}\left(\mathrm{mL} / \mathrm{m}^{2}\right)$ & $28.05 \pm 7.36$ & $78.04 \pm 37.83$ & $89.27 \pm 36.74$ \\
\hline $\operatorname{SVI}\left(\mathrm{mL} / \mathrm{m}^{2}\right)$ & $44.79 \pm 8.69$ & $27.53 \pm 12.42$ & $26.78 \pm 7.90$ \\
\hline LVEF $(\%)$ & $67.45 \pm 12.76$ & $29.15 \pm 11.80$ & $24.65 \pm 8.74$ \\
\hline $\mathrm{CI}\left(\mathrm{L} \cdot \min ^{-1} \cdot \mathrm{m}^{-2}\right)$ & $2.87 \pm 0.58$ & $2.18 \pm 1.22$ & $1.95 \pm 0.55$ \\
\hline $\mathrm{SI}_{\mathrm{d}}$ & $0.61 \pm 0.08$ & $0.61 \pm 0.07$ & $0.60 \pm 0.07$ \\
\hline $\mathrm{SI}_{\mathrm{s}}$ & $0.52 \pm 0.10$ & $0.59 \pm 0.08$ & $0.54 \pm 0.08^{*}$ \\
\hline $\mathrm{vSI}_{\mathrm{d}}$ & $0.28 \pm 0.07$ & $0.33 \pm 0.11$ & $0.33 \pm 0.10$ \\
\hline $\mathrm{vSI}_{\mathrm{s}}$ & $0.25 \pm 0.15$ & $0.29 \pm 0.10$ & $0.29 \pm 0.09$ \\
\hline $\mathrm{EI}_{\mathrm{d}}$ & $0.78 \pm 0.06$ & $0.79 \pm 0.05$ & $0.79 \pm 0.05$ \\
\hline $\mathrm{EI}_{\mathrm{s}}$ & $0.85 \pm 0.07$ & $0.81 \pm 0.05$ & $0.84 \pm 0.05^{*}$ \\
\hline $\mathrm{ACR}_{\mathrm{d}}$ & $1.24 \pm 0.09$ & $1.35 \pm 0.08$ & $1.64 \pm 0.14 \dagger$ \\
\hline $\mathrm{ACR}_{\mathrm{s}}$ & $1.28 \pm 0.15$ & $1.32 \pm 0.12$ & $1.78 \pm 0.26 \dagger$ \\
\hline
\end{tabular}

$I H D$, Ischemic heart disease; $L V A$, left ventricular aneurysm; $L A_{d}$, length of diastolic long axis; $L A_{s}$, length of systolic long axis; $S A_{d}$, length of diastolic short axis; $S A_{s}$, length of systolic short axis; $E D V I$, end-diastolic volume index; $E S V I$, end-systolic volume index; $S V I$, stroke volume index; $L V E F$, left ventricular ejection fraction; $C I$, cardiac index; $S I_{d}$, diastolic sphericity index; $S I_{s}$, systolic sphericity index; $v S I_{d}$, diastolic volumetric sphericity index; $v S I_{s}$, systolic volumetric sphericity index; $E I_{d}$, diastolic eccentricity index; $E I_{s}$, systolic eccentricity index; $A C R_{d}$, diastolic apical conicity ratio; $A C R_{s}$, systolic apical conicity ratio. LVA versus non-LVA. $* P<.05 . \dagger P<.01$.

it may be evaluated by calculating apical deformation. An index had been introduced to analyze left ventricular apical shape, but its method of measurement was questionable. ${ }^{16}$ Accordingly, we introduced a new index using the ratio of the area of apex over the area of apical triangle to evaluate the apical deformation induced by myocardial infarction.

Inasmuch as ACR represented impaired left ventricular apical conical configuration, the increased values indicated an increased degree of disruption of the normal apical conical shape. In patients with LVA, ACR increased significantly and got back to normal level after ventricular reconstruction whereas other global indices such as SI, vSI, and EI remained. On the other hand, in DCM patients, SI, vSI, and EI increased significantly without ACR changes. Among IHD patients, ACR of the LVA group was significantly higher than that of the non-LVA group when the other indices between the 2 groups showed no statistically significant difference. ROC curves showed only ACR had high power of discriminating LVA from non-LVA. Besides, in patients with IHD, ACR demonstrated a modest significant correlation with scar score, which indicates that ACR not only reflects the change of regional shape, but also denotes the extent of impairment of the left ventricle.

In view of the intrinsic disadvantages of MRI, such as sensitivity to motion, noise, long processing times, requirements for breath holding, and possible sensitivity to claustrophobia, alternatively, ACR should be available on other 
imaging modalities such as echocardiography, which is not included in this study. Indeed, we proposed that similar measurements on other imaging modalities may decrease the accuracy.

At the same time, it was noted that in patients with lateral LVA, the ACR tended to be underestimated the values of real apical shape deformation. However, practically, about $85 \%$ of LVAs are located anterolateral to the apex. Few cases were confined to the lateral (obtuse marginal) area, and almost all the lateral aneurysms were false aneurysms. ${ }^{28}$

\section{CONCLUSIONS}

The new index, ACR, can be used to quantify regional left ventricular deformation, especially in patients with LVA resulting from myocardial infarction.

\section{References}

1. Buckberg GD. Ventricular structures must be understood during surgical restoration for heart failure. Scand J Surg. 2007;96:164-76.

2. Menicanti L, Di Donato M. The Dor procedure: what has changed after fifteen years of clinical practice? J Thorac Cardiovasc Surg. 2002;124:886-90.

3. Buckberg GD. Ventricular restoration - a surgical approach to reverse ventricular remodeling. Heart Fail Rev. 2004;9:233-9; discussion 347-51.

4. Buckberg GD. Basic science review: the helix and the heart. J Thorac Cardiovasc Surg. 2002;124:863-83.

5. Marchenko AV, Cherniavsky AM, Volokitina TL, Alsov SA, Karaskov AM. Left ventricular dimension and shape after postinfarction aneurysm repair. Eur J Cardiothorac Surg. 2005;27:475-80; discussion 80.

6. Di Donato M, Sabatier M, Dor V, Gensini GF, Toso A, Maioli M, et al. Effects of the Dor procedure on left ventricular dimension and shape and geometric correlates of mitral regurgitation one year after surgery. J Thorac Cardiovasc Surg. 2001;121:91-6.

7. Kass DA, Traill TA, Keating M, Altieri PI, Maughan WL. Abnormalities of dynamic ventricular shape change in patients with aortic and mitral valvular regurgitation: assessment by Fourier shape analysis and global geometric indexes. Circ Res. 1988;62:127-38.

8. Azancot A, Caudell TP, Allen HD, Horowitz S, Sahn DJ, Stoll C, et al. Analysis of ventricular shape by echocardiography in normal fetuses, newborns, and infants. Circulation. 1983;68:1201-11.

9. Patel AR, Lima C, Parro A, Arsenault M, Vannan MA, Pandian NG. Echocardiographic analysis of regional and global left ventricular shape in Chagas' cardiomyopathy. Am J Cardiol. 1998;82:197-202.

10. Pelliccia A, Avelar E, De Castro S, Pandian N. Global left ventricular shape is not altered as a consequence of physiologic remodeling in highly trained athletes. Am J Cardiol. 2000;86:700-2, A9.

11. Wu H, Hu S, Zhou Y. Operative outcome of patients with left ventricular giant aneurysm: mid-term follow-up in 49 patients. Chin J Surg. 2001;39:928-30.
12. Zheng Z, Fan H, Feng W, Zhang S, Yuan X, Wang L, et al. Surgery of left ventricular aneurysm: a propensity score-matched study of outcomes following different repair techniques. Interact Cardiovasc Thorac Surg. 2009;9: 431-6.

13. Cerqueira MD, Weissman NJ, Dilsizian V, Jacobs AK, Kaul S, Laskey WK, et al Standardized myocardial segmentation and nomenclature for tomographic imaging of the heart: a statement for healthcare professionals from the Cardiac Imaging Committee of the Council on Clinical Cardiology of the American Heart Association. Circulation. 2002;105:539-42.

14. Wu E, Judd RM, Vargas JD, Klocke FJ, Bonow RO, Kim RJ. Visualisation of presence, location, and transmural extent of healed Q-wave and non-Q-wave myocardial infarction. Lancet. 2001;357:21-8.

15. Ueno T, Sakata R, Iguro Y, Yamamoto H, Ueno M, Matsumoto K. Mid-term changes of left ventricular geometry and function after Dor, SAVE, and Overlapping procedures. Eur J Cardiothorac Surg. 2007;32:52-7.

16. Di Donato M, Dabic P, Castelvecchio S, Santambrogio C, Brankovic J, Collarini L, et al. Left ventricular geometry in normal and post-anterior myocardial infarction patients: sphericity index and "new" conicity index comparisons. Eur J Cardiothorac Surg. 2006;29(Suppl 1):S225-30.

17. Youden WJ. Index for rating diagnostic tests. Cancer. 1950;3:32-5.

18. Hutchins GM, Bulkley BH, Moore GW, Piasio MA, Lohr FT. Shape of the human cardiac ventricles. Am J Cardiol. 1978;41:646-54.

19. Hutchins GM, Brawley RK. The influence of cardiac geometry on the results of ventricular aneurysm repair. Am J Pathol. 1980;99:221-30.

20. Azhari H, Buchalter M, Sideman S, Shapiro E, Beyar R. A conical model to describe the nonuniformity of the left ventricular twisting motion. Ann Biomed Eng. 1992;20:149-65

21. Velagaleti RS, Gona P, Levy D, Aragam J, Larson MG, Tofler GH, et al. Relations of biomarkers representing distinct biological pathways to left ventricular geometry. Circulation. 2008;118:2252-8, 5p following 2258.

22. Bluemke DA, Kronmal RA, Lima JA, Liu K, Olson J, Burke GL, et al. The relationship of left ventricular mass and geometry to incident cardiovascular events: the MESA (Multi-Ethnic Study of Atherosclerosis) study. J Am Coll Cardiol. 2008;52:2148-55.

23. Saba MM, Arain SA, Lavie CJ, Abi-Samra FM, Ibrahim SS, Ventura HO, et al. Relation between left ventricular geometry and transmural dispersion of repolarization. Am J Cardiol. 2005;96:952-5.

24. Sehgal S, Drazner MH. Left ventricular geometry: does shape matter? Am Heart J. 2007; 153:153-5

25. Moustakidis P, Maniar HS, Cupps BP, Absi T, Zheng J, Guccione JM, et al Altered left ventricular geometry changes the border zone temporal distribution of stress in an experimental model of left ventricular aneurysm: a finite element model study. Circulation. 2002;106(12 Suppl. 1):I168-75.

26. Matsumoto M, Watanabe F, Goto A, Hamano Y, Yasui K, Minamino T, et al. Left ventricular aneurysm and the prediction of left ventricular enlargement studied by two-dimensional echocardiography: quantitative assessment of aneurysm size in relation to clinical course. Circulation. 1985;72:280-6.

27. Dor V, Saab M, Coste P, Kornaszewska M, Montiglio F. Left ventricular aneurysm: a new surgical approach. Thorac Cardiovasc Surg. 1989;37:11-9.

28. Kouchoukos NT, Blackstone EH, Doty DB, Hanley FL, Karp RB. Kirklin/ Barratt-Boyes cardiac surgery. 3rd ed. Philadelphia: Churchill Livingstone; 2003. 


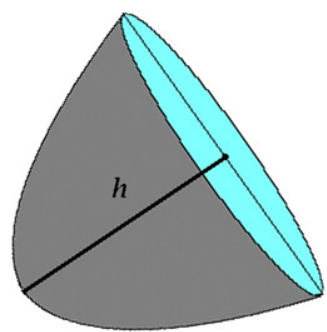

A

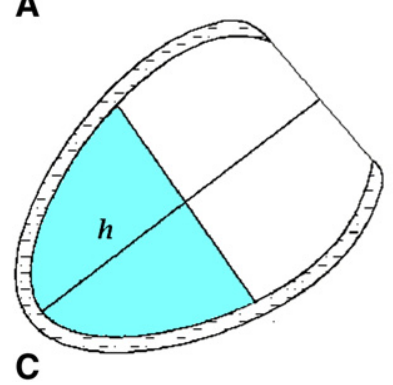

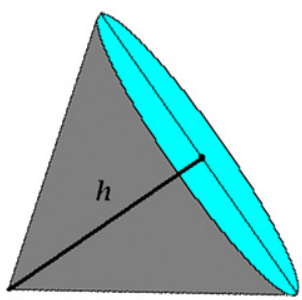

B

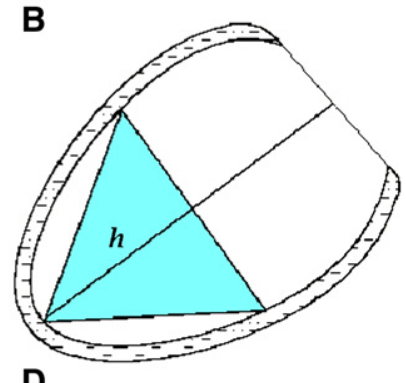

FIGURE E1. Apex of left ventricle and circular cone. A, Normal apex of left ventricle. B, A regular circular cone with the height $(h)$ equal to that of apex. $\mathrm{C}$, View of cross section of apex of left ventricle in 2-dimension image. D, View of cross section of circular cone with the height equal to that of apex in 2-dimension image.
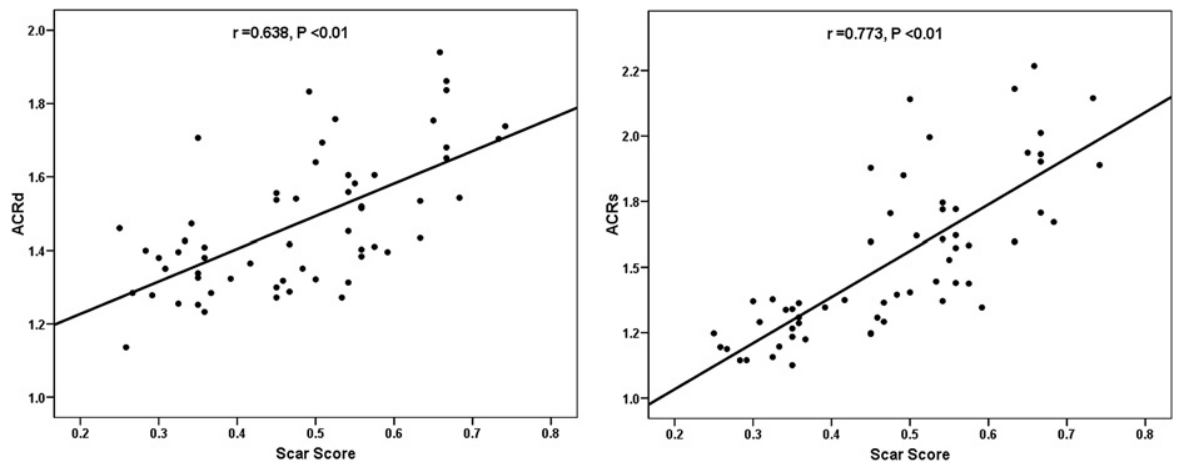

FIGURE E2. Correlations between ACR and scar score. ACRd and ACRs, Diastolic and systolic apical conicity ratio. 

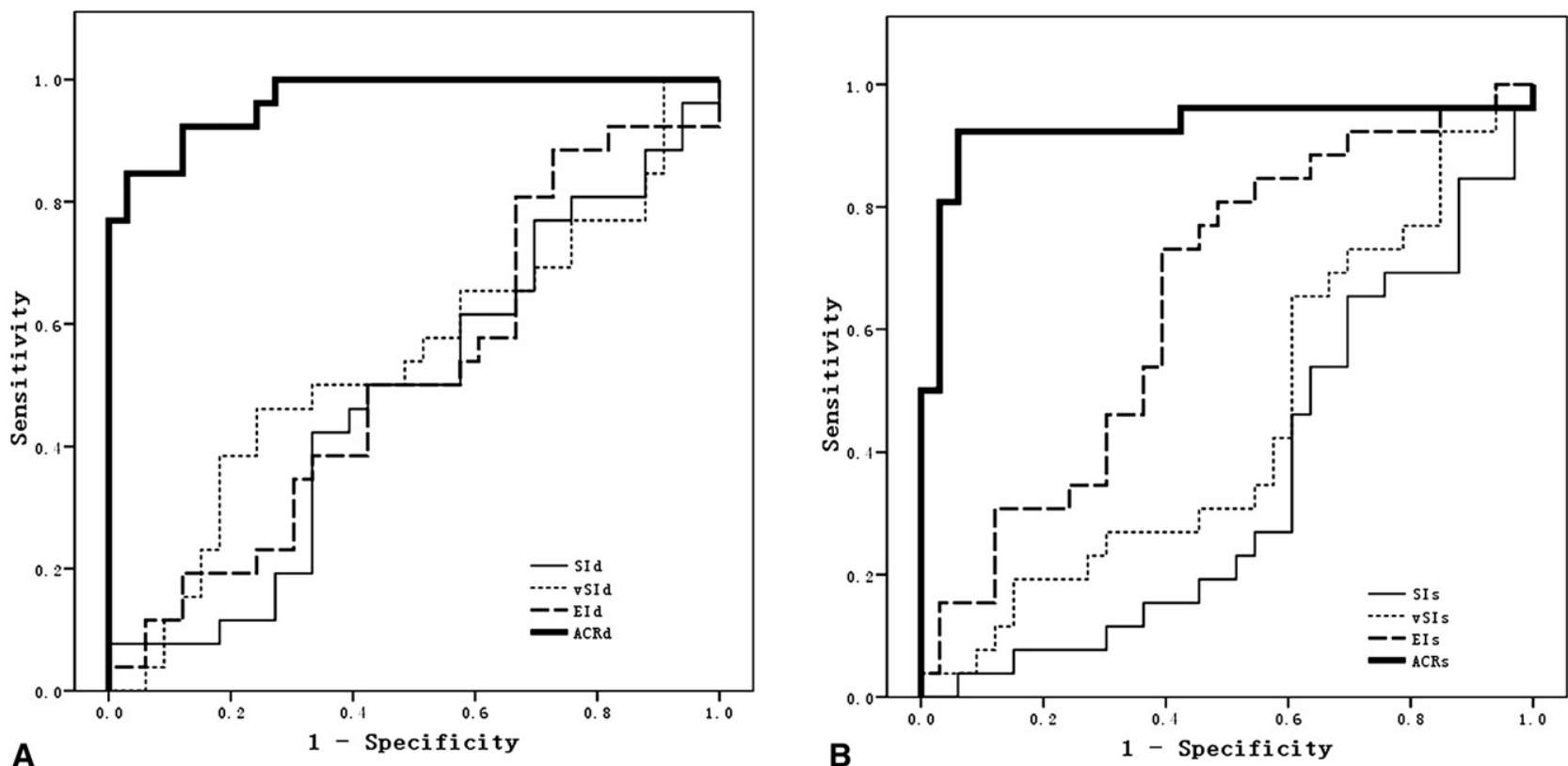

FIGURE E3. Receiver operating characteristic curves for discrimination between LVA and non-LVA by systolic and diastolic sphericity index (SIs and SId), systolic and diastolic volumetric sphericity index ( $v S I s$ and $v S I d$ ), systolic and diastolic eccentricity index (EIs and EId), and systolic and diastolic apical conicity ratio (ACRs and $A C R d$ ). LVA, Left ventricular aneurysm. A, Based on the measurements of diastolic images. B, Based on the measurements of systolic images.

TABLE E1. Preoperative and postoperative general left ventricular geometry and heart function in LVA patients $(n=26)$

\begin{tabular}{lccr}
\hline & Preoperative & Postoperative & P value \\
\hline $\mathrm{LA}_{\mathrm{d}}(\mathrm{cm})$ & $10.16 \pm 0.91$ & $8.21 \pm 1.14$ & $<.001$ \\
$\mathrm{LA}_{\mathrm{s}}(\mathrm{cm})$ & $9.72 \pm 0.99$ & $7.59 \pm 0.97$ & $<.001$ \\
$\mathrm{SA}_{\mathrm{d}}(\mathrm{cm})$ & $6.01 \pm 0.52$ & $5.39 \pm 0.86$ & .001 \\
$\mathrm{SA}(\mathrm{cm})$ & $5.13 \pm 0.70$ & $4.34 \pm 0.93$ & $<.001$ \\
$\mathrm{EDVI}\left(\mathrm{mL} / \mathrm{m}^{2}\right)$ & $93.75 \pm 25.25$ & $63.74 \pm 22.67$ & $<.001$ \\
$\mathrm{ESVI}\left(\mathrm{mL} / \mathrm{m}^{2}\right)$ & $69.11 \pm 26.17$ & $37.73 \pm 17.13$ & $<.001$ \\
$\mathrm{SVI}\left(\mathrm{mL} / \mathrm{m}^{2}\right)$ & $24.27 \pm 6.44$ & $24.14 \pm 9.52$ & .953 \\
$\mathrm{LVEF}(\%)$ & $27.79 \pm 8.76$ & $40.44 \pm 9.52$ & $<.001$ \\
$\mathrm{CI}\left(\mathrm{L} \cdot \mathrm{min}^{-1} \cdot \mathrm{m}^{-2}\right)$ & $1.75 \pm 0.40$ & $1.94 \pm 0.62$ & .239 \\
\hline
\end{tabular}

$L V A$, Left ventricular aneurysm; $L A_{d}$, length of diastolic long axis; $L A_{s}$, length of systolic long axis; $S A_{d}$, length of diastolic short axis; $S A_{s}$, length of systolic short axis; $E D V I$, end-diastolic volume index; $E S V I$, end-systolic volume index; SVI, stroke volume index; $L V E F$, left ventricular ejection fraction; $C I$, cardiac index. 
TABLE E2. Area under curve (AUC) and optimal cutoff values obtained for LVA on 59 patients with ischemic heart disease (26 LVA and 33 nonLVA)

\begin{tabular}{|c|c|c|c|c|c|c|}
\hline Shape indices & AUC & $P$ value & $95 \%$ CI & Optimal cutoff & Sensitivity & Specificity \\
\hline $\mathrm{SI}_{\mathrm{d}}$ & 0.484 & .831 & $0.333-0.634$ & - & - & - \\
\hline $\mathrm{SI}_{\mathrm{s}}$ & 0.347 & .045 & $0.206-0.488$ & - & - & - \\
\hline $\mathrm{vSI}_{\mathrm{d}}$ & 0.540 & .604 & $0.387-0.693$ & - & - & - \\
\hline $\mathrm{vSI}_{\mathrm{s}}$ & 0.450 & .511 & $0.300-0.600$ & - & - & - \\
\hline $\mathrm{EI}_{\mathrm{d}}$ & 0.516 & .831 & $0.366-0.667$ & - & - & - \\
\hline $\mathrm{EI}_{\mathrm{s}}$ & 0.653 & .045 & $0.512-0.794$ & - & - & - \\
\hline $\mathrm{ACR}_{\mathrm{d}}$ & 0.969 & $<.001$ & $0.933-1.005$ & 1.43 & $92.3 \%$ & $87.9 \%$ \\
\hline $\mathrm{ACR}_{\mathrm{s}}$ & 0.929 & $<.001$ & $0.846-1.012$ & 1.49 & $92.3 \%$ & $93.9 \%$ \\
\hline
\end{tabular}

$\overline{L V A}$, Left ventricular aneurysm; $C I$, confidence interval $S I_{d}$, diastolic sphericity index; $S I_{s}$, systolic sphericity index; $v S I_{d}$, diastolic volumetric sphericity index; $v S I_{s}$, systolic volumetric sphericity index; $E I_{d}$, diastolic eccentricity index; $E I_{s}$, systolic eccentricity index; $A C R_{d}$, diastolic apical conicity ratio; $A C R_{s}$, systolic apical conicity ratio. 